\title{
Is early anticoagulation with warfarin necessary after bioprosthetic aortic valve replacement?
}

T. M. Sundt, MD, K. J. Zehr, MD, J. A. Dearani, MD, R. C. Daly, MD, C. J. Mullany, MBMS, C. G. A. McGregor, MD, F. J. Puga, MD, T. A. Orszulak, MD, and H. V. Schaff, MD

From the Division of Cardiovascular Surgery, Mayo Clinic, Rochester, Minn.

Read at the Thirtieth Annual Meeting of The Western Thoracic Surgical Association, Maui, Hawaii, June 23-26, 2004.

Received for publication June 21, 2004; revisions received Nov 18, 2004; accepted for publication Nov 23, 2004

Address for reprints: Thoralf M. Sundt III, MD, Division of Cardiovascular Surgery, Mayo Clinic, 200 First St SW, Rochester, MN 55905 (E-mail: sundt.thoralf@mayo. edu).

J Thorac Cardiovasc Surg 2005;129: $1024-31$

$0022-5223 / \$ 30.00$

Copyright (C) 2005 by The American Association for Thoracic Surgery

doi:10.1016/j.jtcvs.2004.11.028
Objectives: Freedom from anticoagulation is the principal advantage of bioprosthesis; however, the American Heart Association/American College of Cardiology and the American College of Chest Physicians guidelines recommend early anticoagulation with heparin, followed by warfarin for 3 months after bioprosthetic aortic valve replacement. We examined neurologic events within 90 days of bioprosthetic aortic valve replacement at our institution.

Methods: Between 1993 and 2000, 1151 patients underwent bioprosthetic aortic valve replacement with (641) or without (510) associated coronary artery bypass. By surgeon preference, 624 had early postoperative anticoagulation $(\mathrm{AC}+)$ and $527 \mathrm{did}$ not (AC-). In the AC- group, 410 patients (78\%) received antiplatelet therapy. Groups were similar with respect to gender (female, $36 \% \mathrm{AC}+$ vs $40 \% \mathrm{AC}-, P=$ $.21)$, hypertension $(64 \% \mathrm{AC}+\mathrm{vs} 61 \%, P=.27)$, and prior stroke $(7.6 \% \mathrm{AC}+\mathrm{vs}$ $8.5 \%$ AC-,$P=.54)$. The AC + group was slightly younger than the AC- group (median, 76 years vs 78 years, $P=.006$ ).

Results: Operative mortality was $4.1 \%$ with $43(3.7 \%)$ cerebrovascular events within 90 days. Excluding 18 deficits apparent upon emergence from anesthesia, we found that postoperative cerebrovascular accident occurred in $2.4 \%$ of $\mathrm{AC}+$ and $1.9 \%$ AC- patients. By multivariable analysis, the only predictor of operative mortality was hypertension $(P<.0001)$. Postoperative cerebrovascular accident was unrelated to warfarin use $(P=.32)$. The incidence of mediastinal bleeding requiring reexploration was similar $(5.0 \%$ vs $7.4 \%)$, as were other bleeding complications in the first 90 days $(1.1 \%$ vs $0.8 \%)$. No variables were predictive of bleeding by multivariate analysis.

Conclusions: Although these data do not address the role of antiplatelet agents, early anticoagulation with warfarin after bioprosthetic aortic valve replacement did not appear to protect against neurologic events.

$\mathrm{T}$ he principal advantage of biological aortic valve prostheses over mechanical prostheses is freedom from anticoagulation. Accordingly, bioprostheses are used commonly in elderly patients and in others in whom the risks associated with anticoagulation are believed to be high. Long-term results with tissue valves have shown a low incidence of complications ${ }^{1}$; however, early thromboembolic events, particularly with bioprostheses in the mitral position, have been reported. ${ }^{2}$ Accordingly, the guidelines for valve replacement developed by the American Heart Association and American College of Cardiology (AHA/ACC) ${ }^{3}$ and by the American College of Chest Physicians (ACCP) ${ }^{4}$ recommend early anticoagulation with heparin, followed by warfarin for the first 3 months after bioprosthetic aortic valve replacement (AVR). Similar recommendations have been made by the European Society of Cardiology as well. ${ }^{5}$ 
TABLE 1. Demographics

\begin{tabular}{|c|c|c|c|c|}
\hline & $\begin{array}{l}\text { All patients } \\
(\mathrm{n}=1151)\end{array}$ & $\begin{array}{c}\text { Anticoag }+ \\
(n=624)\end{array}$ & $\begin{array}{c}\text { Anticoag - } \\
(\mathrm{n}=527)\end{array}$ & $P$ value \\
\hline \multicolumn{5}{|l|}{ Age (y) } \\
\hline Mean $\pm S D$ & $76.3 \pm 8.1$ & $75.9 \pm 7.6$ & $76.7 \pm 8.6$ & .006 \\
\hline Median & 77 & 76 & 78 & \\
\hline Gender & & & & .209 \\
\hline Male & $717(62.3 \%)$ & $399(63.9 \%)$ & $318(60.3 \%)$ & \\
\hline Female & $434(37.7 \%)$ & $225(36.1 \%)$ & $209(39.7 \%)$ & \\
\hline Hypertension & $721(62.8 \%)$ & $399(64.3 \%)$ & $322(61.1 \%)$ & .271 \\
\hline Prior CVA & $92(8.0 \%)$ & $47(7.6 \%)$ & $45(8.5 \%)$ & .541 \\
\hline Cerebrovascular disease & $169(14.7 \%)$ & $91(14.6 \%)$ & $78(14.9 \%)$ & .896 \\
\hline Renal insufficiency $(\mathrm{Cr}>2)$ & $57(5.2 \%)$ & $26(4.3 \%)$ & $31(6.4 \%)$ & .118 \\
\hline Diabetes & $224(19.5 \%)$ & $130(20.9 \%)$ & $94(17.8 \%)$ & .196 \\
\hline COPD & $166(14.4 \%)$ & $95(15.2 \%)$ & $71(13.5 \%)$ & .399 \\
\hline Prior MI & $192(16.7 \%)$ & $108(17.4 \%)$ & $84(16.0 \%)$ & .520 \\
\hline NYHA class & & & & .443 \\
\hline Class I & $49(4.3 \%)$ & $26(4.2 \%)$ & $23(4.4 \%)$ & \\
\hline Class II & $176(15.3 \%)$ & $100(16.1 \%)$ & $76(14.5 \%)$ & \\
\hline Class III & $728(63.5 \%)$ & $395(63.5 \%)$ & $333(63.4 \%)$ & \\
\hline Class IV & $194(16.9 \%)$ & $101(16.2 \%)$ & $93(17.7 \%)$ & \\
\hline Endocarditis & $16(1.4 \%)$ & $12(1.9 \%)$ & $4(0.8 \%)$ & .093 \\
\hline Atrial fibrillation at surgery & $68(5.9 \%)$ & $41(6.6 \%)$ & $27(5.1 \%)$ & .300 \\
\hline $\begin{array}{l}\text { History of atrial fibrillation (not } \\
\text { in AFib at time of surgery) }\end{array}$ & $96(8.3 \%)$ & $58(9.3 \%)$ & $38(7.2 \%)$ & .203 \\
\hline Aortic stenosis only & & $120(19.2 \%)$ & $91(17.3 \%)$ & .391 \\
\hline Aortic regurgitation only & & $36(5.8 \%)$ & $27(5.1 \%)$ & 631 \\
\hline Aortic stenois and regurgitation & & $467(74.8 \%)$ & $407(77.2 \%)$ & .345 \\
\hline \multicolumn{5}{|l|}{ Ejection fraction } \\
\hline Mean $\pm S D$ & $56.4 \pm 15.2$ & $56.7 \pm 15.1$ & $56.1 \pm 15.3$ & .602 \\
\hline Median & 60 & 60 & 60 & \\
\hline Ejection fraction $<30 \%$ & $74(6.6 \%)$ & $41(6.8 \%)$ & $33(6.4 \%)$ & .789 \\
\hline Hypercholesterolemia & $682(59.9 \%)$ & $378(61.4 \%)$ & $304(58.1 \%)$ & .267 \\
\hline $\mathrm{CAD}$ & $788(68.5 \%)$ & $419(67.3 \%)$ & $369(70.0 \%)$ & .315 \\
\hline Left main disease $>50 \%$ & $129(11.7 \%)$ & $69(11.6 \%)$ & $60(11.9 \%)$ & .859 \\
\hline Previous CABG & $120(10.4 \%)$ & $66(10.6 \%)$ & $54(10.3 \%)$ & .855 \\
\hline Preop anticoagulant & $267(23.2 \%)$ & $154(24.7 \%)$ & $113(21.4 \%)$ & .195 \\
\hline Preop aspirin & $640(55.6 \%)$ & $336(53.9 \%)$ & $304(57.7 \%)$ & .192 \\
\hline Preop nonaspirin antiplatelet & $33(3.3 \%)$ & $23(4.2 \%)$ & $10(2.3 \%)$ & .095 \\
\hline Left ventricular hypertrophy & $328(28.5 \%)$ & $170(27.2 \%)$ & $158(30.0 \%)$ & .305 \\
\hline
\end{tabular}

Anticoag +, Receiving heparin and warfarin; Anticoag -, not receiving heparin and warfarin; CVA, cerebrovascular accident; $C O P D$; chronic obstructive pulmonary disease; MI, myocardial infarction; NYHA, New York Heart Association; AFib, atrial fibrillation; CAD, coronary artery disease; $C A B G$, coronary artery bypass graft; preop, preoperative.

Early anticoagulant therapy is intended to provide protection from thromboembolic events while the cloth sewing ring is endothelialized. The recommended duration of warfarin therapy may be viewed as brief; unfortunately, the risks of anticoagulant-related hemorrhage are highest during the first 3 months of therapy. ${ }^{6}$ The recommended strategy, therefore, subjects those patients we are most reluctant to anticoagulate to a significant risk of complications.

Despite the published guidelines, opinion and practice with regard to anticoagulation in the first 90 days after bioprosthetic valve replacement remains divided. Indeed, the aforementioned guidelines themselves are somewhat inconsistent, with the AHA/ACC panel judging early anticoagulation a class I indication, whereas the authors of the ACCP guidelines grade the evidence for this to be only 2C. Furthermore, the British Society of Hematologists recommends only antiplatelet therapy after biological AVR. ${ }^{6}$

The practice in our own institution reflects this diversity of opinion. After publication of a Mayo Clinic study advocating intravenous heparin starting the day after surgery followed by warfarin therapy for 3 months, ${ }^{7}$ some surgeons 
TABLE 2. Operative characteristics

\begin{tabular}{|c|c|c|c|c|}
\hline & $\begin{array}{l}\text { All patients } \\
\text { (n = 1151) }\end{array}$ & $\begin{array}{c}\text { Anticoag + } \\
\text { (n = 624) }\end{array}$ & $\begin{array}{c}\text { Anticoag - } \\
\text { (n = 527) }\end{array}$ & $P$ value \\
\hline Concomitant CABG & $641(55.7 \%)$ & $338(54.2 \%)$ & $303(57.5 \%)$ & .257 \\
\hline \multicolumn{5}{|l|}{ Crossclamp time } \\
\hline Mean $\pm S D$ & $64.0 \pm 23.7$ & $69.5 \pm 23.3$ & $57.6 \pm 22.6$ & $<.001$ \\
\hline Median & 59.5 & 67 & 53 & \\
\hline \multicolumn{5}{|l|}{ Bypass time } \\
\hline Mean $\pm S D$ & $97.5 \pm 40.6$ & $106.6 \pm 37.3$ & $86.6 \pm 41.8$ & $<.001$ \\
\hline Median & 89 & 101 & 79 & \\
\hline Prosthesis inserted & & & & .002 \\
\hline Porcine & $412(35.8 \%)$ & $248(39.7 \%)$ & $164(31.1 \%)$ & \\
\hline Bovine & $739(64.2 \%)$ & $376(60.3 \%)$ & $363(68.9 \%)$ & \\
\hline Status & & & & .793 \\
\hline Elective & $1107(96.2 \%)$ & $602(96.5 \%)$ & $505(95.8 \%)$ & \\
\hline Urgent & $37(3.2 \%)$ & $19(3.1 \%)$ & $18(3.4 \%)$ & \\
\hline Emergency & $7(0.6 \%)$ & $3(0.5 \%)$ & $4(0.8 \%)$ & \\
\hline IABP & & & 4 & \\
\hline Preop insertion & $5(0.4 \%)$ & $1(0.2 \%)$ & $5(0.8 \%)$ & .185 \\
\hline Intraop insertion & $36(3.1 \%)$ & $14(2.2 \%)$ & $22(4.2 \%)$ & .061 \\
\hline VAD & $1(0.1 \%)$ & $0(0.0 \%)$ & $1(0.2 \%)$ & .458 \\
\hline
\end{tabular}

Anticoag + , Receiving heparin and warfarin; Anticoag -, not receiving heparin and warfarin; $C A B G$, coronary artery bypass grafting; preop, preoperative; intraop, intraoperative; $I A B P$, intra-aortic balloon pump; $V A D$, ventricular assist device.

in our group adopted this approach, whereas others did not. This diversity in practice pattern, therefore, provides 2 groups of patients for retrospective analysis of the impact of warfarin therapy on cerebral ischemic events during the first 90 days after bioprosthetic AVR.

\section{Methods}

After obtaining appropriate institutional review board approval, a retrospective analysis of patients undergoing bioprosthetic AVR between January 1993 and January 2000 was undertaken. Cases were identified by a search of our computerized clinical database. Patients undergoing associated coronary artery bypass were included; those undergoing other concomitant procedures were not.
Follow-up was obtained between September 6, 2002, and December 1, 2003. Hospital charts of all patients were reviewed and abstracted for in-hospital events and any subsequent events noted in the hospital record. In-hospital follow-up was $100 \%$ complete. Ninety-day follow-up was not routinely collected prospectively. Accordingly, postal questionnaires were mailed to patients alive at the time of follow-up and telephone calls made to those not responding to the postal questionnaire. Information regarding anticoagulant use and thromboembolic or other neurologic events out to 90 days was obtained through one of these means in $87 \%$ of patients.

All suspected cerebral ischemic events were reviewed and adjudicated by one of the authors (T.M.S.) blinded to the treatment

TABLE 3. Operative results

\begin{tabular}{|c|c|c|c|c|}
\hline & $\begin{array}{c}\text { All patients } \\
\text { (n = 1151) }\end{array}$ & $\begin{array}{c}\text { Anticoag }+ \\
(n=624)\end{array}$ & $\begin{array}{c}\text { Anticoag - } \\
(\mathrm{n}=527)\end{array}$ & $P$ value \\
\hline Mortality (operative) & $47(4.1 \%)$ & $6(1.0 \%)$ & $41(7.8 \%)$ & $<.001$ \\
\hline Reexploration for bleeding & $70(6.1 \%)$ & $31(5.0 \%)$ & $39(7.4 \%)$ & .085 \\
\hline $\mathrm{Ml}$ & $6(0.5 \%)$ & $3(0.5 \%)$ & $3(0.6 \%)$ & 1.000 \\
\hline Postop IABP & $7(0.6 \%)$ & $1(0.2 \%)$ & $6(1.1 \%)$ & .052 \\
\hline $\begin{array}{l}\text { Renal failure (patients with preop renal } \\
\text { failure not included) }\end{array}$ & $5(0.5 \%)$ & $0(0.0 \%)$ & $5(1.0 \%)$ & .019 \\
\hline \multicolumn{5}{|l|}{ Postop LOS } \\
\hline Mean $\pm S D$ & $10.3 \pm 9.1$ & $9.6 \pm 5.5$ & $11.2 \pm 12.1$ & .741 \\
\hline Median & 8 & 8 & 8 & \\
\hline
\end{tabular}

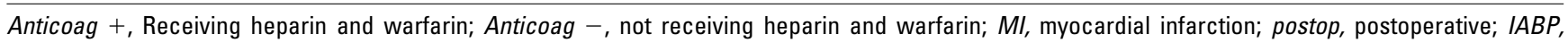
intra-aortic balloon pump; preop, preoperative; LOS, length of stay. 
TABLE 4. Primary end points of stroke and bleeding

\begin{tabular}{lccc}
\hline & $\begin{array}{c}\text { All patients } \\
\text { (n= 1151) }\end{array}$ & $\begin{array}{c}\text { Anticoag }+ \\
\text { (n = 624) }\end{array}$ & $\begin{array}{c}\text { Anticoag - } \\
\text { (n= 527) }\end{array}$ \\
\hline CVA & & & \\
Intraop & 18 & 9 & 9 \\
$<30$ days & 19 & 11 & 8 \\
30-90 days & 6 & 5 & 1 \\
In-hospital reexploration & 74 & 32 & 42 \\
Out-of-hospital bleeding & 11 & 7 & 4 \\
$\quad$ event & & & \\
\hline
\end{tabular}

Anticoag + , Receiving heparin and warfarin; Anticoag -, not receiving heparin and warfarin; CVA, cerebrovascular accident; intraop, intraoperative.

group. Postoperative delirium was not scored as stroke. Patients in whom a deficit developed after they had awakened intact from anesthesia were scored as having a postoperative event, while those awakening with a deficit or those never regaining consciousness postoperatively were scored as having intraoperative events. Because of the realities of clinical practice, a strict definition of thromboembolic stroke was frequently not possible from the hospital record. In some cases, the consulting neurologist speculated with regard to etiology, distinguishing embolic from hypertensive or hypotensive infarction, but this was not uniform. Accordingly, in the interest of an inclusive data set, either a clinical diagnosis of stroke or evidence of cerebral infarction by computed tomographic or magnetic resonance imaging was accepted as evidence of a cerebral ischemic event. There was only 1 reversible cerebral ischemic event identified within the 90-day interval. No peripheral embolic events were identified.

Members of the Division of Cardiovascular Surgery, Mayo Clinic Rochester, performed all operations. Mild hypothermic or normothermic cardiopulmonary bypass was routine. Cardioplegic arrest was achieved by blood or crystalloid cardioplegia, per the individual surgeon's preference. The prosthesis type inserted was also at the discretion of the operating surgeon.

Postoperative management was at the discretion of the individual surgeon. Some members of the division routinely anticoagulated patients, beginning intravenous heparin within 24 hours of surgery and converting to warfarin before discharge from the hospital. Others were treated with aspirin only or no anticoagulant at all. Of patients not receiving warfarin, $78 \%$ received antiplatelet therapy. Patients experiencing atrial fibrillation were routinely administered anticoagulants before discharge. Patients were allocated to $\mathrm{AC}+$ (early postoperative anticoagulation with heparin and warfarin) or AC- (no anticoagulation ) groups on the basis of medications at the time of discharge from the hospital or at the time of in-hospital stroke, if such occurred.

\section{Statistical Analysis}

Categorical factors were compared between groups by using Fisher exact tests. For groups with severity classifications, such as aortic valve regurgitation, the $P$ value is based on an absent versus present response. Logistic regression models were used to construct a multivariate model to predict operative mortality. A stepwise selection technique was used to identify factors for the final
TABLE 5. Analysis for operative mortality

\begin{tabular}{|c|c|c|c|}
\hline Variable & Odds ratio & $95 \% \mathrm{CI}$ & $P$ value \\
\hline \multicolumn{4}{|l|}{ Univariable } \\
\hline Male & 0.74 & $0.41,1.33$ & .32 \\
\hline Diag of CAD & 1.53 & $0.77,3.04$ & .23 \\
\hline Hypertension & 5.22 & $2.05,13.30$ & .0005 \\
\hline Prior CVA & 2.09 & $0.91,4.82$ & .08 \\
\hline Prior CV intervention & 1.74 & $0.95,3.21$ & .07 \\
\hline Prior CABG & 1.82 & $0.83,3.99$ & .14 \\
\hline CAB done & 0.90 & $0.50,1.62$ & .72 \\
\hline Age & 1.14 & $0.77,1.70$ & .51 \\
\hline \multicolumn{4}{|l|}{ Multivariable } \\
\hline Hypertension & 0.19 & $0.08,0.49$ & $<.0001$ \\
\hline
\end{tabular}

multivariate model. Potential risk factors for long-term endpoints such as stroke outside the intraoperative period were evaluated by the Cox proportional hazards models. Age was adjusted for 10year intervals.

\section{Results}

During the study interval, slightly more than half of the patients undergoing AVR received anticoagulation with heparin and warfarin (AC+ group). As shown in Table 1, the median age of the $\mathrm{AC}+$ group was slightly less than that of the AC-group, although this difference is not likely to be clinically significant. There was no significant difference in gender distribution or in the incidence of hypertension, diabetes, prior cerebrovascular accident, or renal insufficiency. Patients in both groups were of similar New York Heart Association class and had similar ejection fractions. A slightly greater number of patients with endocarditis received aggressive anticoagulation, although this indication for surgical intervention represented only a very small portion of the study group. Similar percentages of patients were in atrial fibrillation at the time of surgery.

Operative characteristics of both study groups were also quite similar (Table 2). Bypass times as well as crossclamp times were slightly longer in the $\mathrm{AC}+$ group, although these differences were not likely of clinical significance. There was no difference in distribution of porcine verses bovine prostheses. A slightly greater number of patients in the ACgroup received intra-aortic balloon pumps intraoperatively; however, this event was uncommon, and the difference did not reach statistical significance.

The operative mortality rate appeared higher in the $\mathrm{AC}-$ group (Table 3 ). Interpretation of this observation is complicated by the retrospective nature of this study, as individuals not surviving the operative interval long enough to receive anticoagulation are necessarily classified as $\mathrm{AC}-$. The higher incidence in the $\mathrm{AC}$ - group of new onset renal 
TABLE 6. Univariable analysis for strokes outside the intraoperative period

\begin{tabular}{lccc}
\hline Variable* $^{*}$ & $\begin{array}{c}\text { Hazard } \\
\text { ratio }\end{array}$ & $\mathbf{9 5 \%}$ Cl & $\boldsymbol{P}$ value \\
\hline Male & 0.65 & $0.29,1.44$ & .29 \\
Diag of CAD & 1.86 & $0.69,5.00$ & .22 \\
Hypertension & 1.54 & $0.64,3.71$ & .34 \\
Prior CVA & 2.24 & $0.75,6.68$ & .15 \\
Prior CV intervention & 0.95 & $0.37,2.39$ & .91 \\
Prior CABG & - & - & .96 \\
CAB done & 1.20 & $0.53,2.69$ & .66 \\
Warfarin & 1.51 & $0.66,3.46$ & .32 \\
Age & 1.48 & $0.81,2.71$ & .20 \\
History of Afib (not in Afib & 0.96 & $0.22,4.11$ & .95 \\
at time of surgery) & & & \\
Afib at surgery & - & - & .97 \\
EF $<30$ & - & - & .97 \\
ASA & 1.02 & $0.45,2.32$ & .97 \\
\hline
\end{tabular}

$\mathrm{Cl}$, Confidence interval; diag, diagnosis; $C A D$, coronary artery disease; $C V A$, cerebrovascular event; $C V$, cardiovascular; $C A B G$, coronary artery bypass grafting; $C A B$, coronary artery bypass; Afib, atrial fibrillation; $E F$, ejection fraction; $A S A$, aspirin. *A stepwise multivariable logistic model was done with all of the above variables. Age has been adjusted for 10 -year intervals. No variables were significant in the multivariable model. Note: The dashes indicate that the hazard ratio and $95 \% \mathrm{Cl}$ were not calculated, because there were no patients with a stroke who had any of these events.

failure, a marker for multisystem dysfunction, supports this interpretation. Importantly, there was no difference between groups with respect to reoperation for bleeding.

Postoperative neurologic events occurred in 43 patients (Table 4). Of these, 18 events were judged likely intraoperative events as noted above. They were excluded from further analysis, as the focus of this study is the impact of postoperative management on postoperative outcome. Among the remaining events, similar numbers occurred in the $\mathrm{AC}+$ and $\mathrm{AC}-$ groups. At the time of the event, 17 patients were in sinus rhythm. Of these 17 patients, 10 were receiving aggressive anticoagulation. A similar distribution prevailed among the 8 patients in atrial fibrillation at the time of stroke, with 5 anticoagulated and 3 not. Unfortunately information regarding the management of the left atrial appendage at surgery is incomplete, although it is not routine in this institution to ligate this structure during AVR.

Univariate analysis of risk factors for operative mortality yielded only hypertension as a predictor (Table 5). No risk factors for postoperative stroke within 90 days, including history of atrial fibrillation, atrial fibrillation at he time of surgery, ejection fraction, or age, were apparent (Table 6) This may be due in part to the small number of events recorded. Postoperative warfarin did not appear protective. Similarly, there was no apparent benefit to aspirin, although
TABLE 7. Univariable analysis for bleeds within 3 months

\begin{tabular}{lclc}
\hline Variable* & Odds ratio & 95\% CI & $\boldsymbol{P}$ value \\
\hline Male & 2.75 & $0.59,12.76$ & .20 \\
Diag of CAD & 0.38 & $0.12,1.25$ & .11 \\
Hypertension & 0.34 & $0.10,1.5$ & .08 \\
Prior CVA & 1.15 & $0.15,9.09$ & .89 \\
Prior CV intervention & 0.66 & $0.14,3.09$ & .60 \\
Prior CABG & 0.86 & $0.11,6.76$ & .88 \\
CAB done & 0.66 & $0.20,2.18$ & .50 \\
Warfarin & 1.49 & $0.43,5.11$ & .53 \\
Age & 0.72 & $0.43,1.19$ & .20 \\
\hline
\end{tabular}

$C l$, Confidence interval; diag, diagnosis; $C A D$, coronary artery disease; $C V A$, cerebrovascular event; $C V$, cardiovascular; $C A B G$, coronary artery bypass grafting; $C A B$, coronary artery bypass. ${ }^{*} A$ stepwise multivariable logistic model was done with all of the above variables. Age has been adjusted for 10 -year intervals. No variables were significant in the multivariable model.

the majority of patients were on this medication. As shown in Table 7, no risk factors achieved significance for postoperative bleeding.

\section{Discussion}

The results of our study demonstrate no apparent benefit to early anticoagulation in the first 90 days after bioprosthetic AVR. While there was no apparent increase in bleeding complications, there was also no reduction in stroke. On the basis of the data presented here, we no longer routinely administer heparin and warfarin to patients after bioprosthetic AVR, although we continue to administer aspirin to most patients. The ever-advancing age of patients undergoing valve replacement and the emphasis on earlier discharge argue in favor of such a selective approach to anticoagulation after bioprosthetic AVR. We agree that factors influencing the risk of thromboembolism, such as age, tobacco abuse, hypertension, diabetes, hyperlipidemia, atrial fibrillation, ventricular function, left atrial size $(>50 \mathrm{~mm}$ on echocardiography), previous thromboembolism, and hypercoagulable states, encourage anticoagulation as suggested by Goldsmith. ${ }^{6}$ Indeed, an argument may be made for the use of mechanical prostheses among patients with strong indications for anticoagulation postoperatively. ${ }^{8}$

Our findings are consonant with those of other investigators. In a retrospective review of patients after bioprosthetic AVR, Moinuddeen and associates ${ }^{9}$ observed no difference in incidence of stroke risk between 109 patients receiving heparin followed by 3 months of warfarin, compared with 76 patients receiving no anticoagulation. In their study, as in ours, the bleeding risk was no higher in the warfarin group. In a review of patients receiving no anticoagulation after tissue AVR, Babin-Ebell and colleagues ${ }^{10}$ observed a stroke rate of only $1.75 \%$ in the first 6 months among 54 patients. No control group was provided; how- 
ever, this rate compares favorably with other series in which early anticoagulation was employed. ${ }^{1}$ These results are consistent with Turpie's ${ }^{11}$ observations that a less-intensive anticoagulant regimen was equally effective and, in fact, safer for patients with tissue valves. Most recently, Gherli and associates ${ }^{12}$ have conducted a prospective randomized study of anticoagulation after bioprosthetic AVR. In their study, there was no difference in cerebral ischemic events between a group of 141 patients receiving warfarin for 3 months and 108 receiving only aspirin. Again, there was also no difference in major bleeding events between the groups.

The results of our current study are at variance with AHA/ACC and ACCP recommendations, as well as with a previous report from our own institution. ${ }^{7}$ This study, published by Heras and colleagues, ${ }^{7}$ provides much of the support for the guidelines as written. In that study, the authors identified a significant risk of neurologic events during the first 3 months after bioprosthetic valve replacement. The overall risk was higher after mitral than AVR and was particularly high in the first 10 days postoperatively. In this interval, there were 5 strokes among 424 patients undergoing bioprosthetic AVR, all of which occurred among patients not receiving anticoagulation. The risk fell precipitously thereafter to a linearized rate of $3.6 \%$ per year between 10 and 90 days, and $1.9 \%$ per year thereafter. The authors concluded that early anticoagulation to an international normalized ratio of 3.0 to 4.5 may be advisable. They did not, however, distinguish between prostheses in the mitral and aortic positions. Curiously, the protective effect of anticoagulation was only slight after mitral valve replacement and was not seen at all among double valve replacement patients. Furthermore, while approximately one third of the patients were given anticoagulants postoperatively, in two thirds of those cases the prothrombin time was less than 1.3 seconds during the high-risk first 10 days when an apparent protective effect was observed.

The explanation for the differences in outcome between our current study and the previous report from our own institution is a matter of speculation. Variations in follow-up are always a consideration, although information for the earliest postoperative interval-when the greatest risk of stroke was identified - should be comparable. Differences in the criteria for stroke could play a role as well, although we attempted to use as inclusive a definition as possible. The most tempting explanation is that the liberal use of platelet inhibitors in current clinical practice has reduced these early events. We support this approach and routinely administer aspirin after bioprosthetic AVR.

Our current study suffers from significant weaknesses to be sure. The retrospective design makes "intention to treat" analysis impossible, complicating the interpretation of data for the $\mathrm{AC}+$ and $\mathrm{AC}-$ groups. The subtle effects of selec- tion bias may also impact any nonrandomized study. Practice patterns during the study interval were relatively consistent within any individual surgeon's practice, however, and referral for AVR within our institution is relatively evenly spread among surgeons. While referral is not random, it is certainly not based on anticoagulation philosophy. Surgeons with larger and smaller total case volumes were also represented in both groups. Follow-up was incomplete as well. Unfortunately, because of current government regulations related to privacy, it is unlikely that more complete information can be obtained in a retrospective study such as this.

As in other retrospective analyses, imprecise definition of the etiology of neurologic events is a difficulty in this study. Review of the hospital records showed that neurologic consultation was not uniform. The choice of imaging studies varied, and the assessment of embolic versus nonembolic etiology was not routinely documented. Subtle events may have been missed. The attribution of some events to the intraoperative period carries the potential for error as well. In contrast to the observations made in the setting of coronary bypass surgery by Hogue and colleagues, ${ }^{13,14}$ a great many of the cerebrovascular accidents observed in the current study appeared to be intraoperative. In their analysis, $65 \%$ of perioperative strokes were delayed. This difference is likely due to the open versus closed nature of the procedures, the potential for embolization of debris from the valve annulus, and the lower incidence of generalized atherosclerosis among patients undergoing AVR.

Finally, despite being the largest study in the literature, our sample size remains far too small to definitively answer the question posed. The data supporting early anticoagulation are remarkably sparse as well, however. The authors of the AHA/ACC guidelines reference only the Heras ${ }^{7}$ paper in support of early anticoagulation. In their consensus report for the ACCP, Stein and colleagues ${ }^{4}$ cited the event rate of $1.8 \%$ without anticoagulation reported by Babin-Ebel ${ }^{10}$ (54 patients), compared with Turpie's ${ }^{11}$ report of no events with heparin and warfarin (109 patients). Although the event rates differ, the exceedingly small numbers of patients in both series make conclusions tenuous at best.

The results presented here may be fairly considered a test of the hypothesis generated by the earlier work from our institution. On the basis of that work, some surgeons in the group were stimulated to pursue an aggressive approach to anticoagulation. The results obtained do not support the notion that early anticoagulation after bioprosthetic AVR reduced stroke risk. Conversely, there was no increased risk of complications. We believe that one can reasonably adopt a posture of equipoise on the matter. The results of this study further suggest that efforts to reduce the risk of cerebral events after AVR might be best directed toward the intraoperative period. Recently introduced devices intended 
to capture ${ }^{15}$ or deflect ${ }^{16,17}$ debris liberated from the aorta or valve intraoperatively may find particular application in this regard.

We gratefully acknowledge the assistance of Judy R. Lenoch, Christina M. Sannes, and Diana L. Lesmeister for their assistance with data collection.

\section{References}

1. Pellerin M, Mihaileanu S, Couetil JP, et al. Carpentier-Edwards pericardial bioprosthesis in aortic position: long-term follow-up 1980 to 1994. Ann Thorac Surg. 1995;60(2 Suppl):S292-5; discussion S295-6.

2. Horstkotte D, Scharf RE, Schultheiss HP. Intracardiac thrombosis: patient-related and device-related factors. J Heart Valve Dis. 1995;4: 114-20.

3. Bonow RO, Carabello B, de Leon AC Jr, et al. Guidelines for the management of patients with valvular heart disease: executive summary: a report of the American College of Cardiology/American Heart Association Task Force on Practice Guidelines (Committee on Management of Patients with Valvular Heart Disease). Circulation. 1998; 98:1949-84.

4. Stein PD, Alpert JS, Bussey HI, et al. Antithrombotic therapy in patients with mechanical and biological prosthetic heart valves. Chest. 2001:119(1 Suppl):220S-7S.

5. Gohlke-Barwolf C, Acar J, Oakley C, et al. Guidelines for prevention of thromboembolic events in valvular heart disease. Study Group of the Working Group on Valvular Heart Disease of the European Society of Cardiology. Eur Heart J. 1995;16:1320-30.

6. Goldsmith I, Turpie AG, Lip GY. Valvar heart disease and prosthetic heart valves. BMJ. 2002;325:1228-31.

7. Heras M, Chesebro JH, Fuster V, et al. High risk of thromboemboli early after bioprosthetic cardiac valve replacement. J Am Coll Cardiol. 1995;25:1111-9.

8. Louagie YA, Jamart J, Eucher P, et al. Mitral valve CarpentierEdwards bioprosthetic replacement, thromboembolism, and anticoagulants. Ann Thorac Surg. 1993;56:931-6; discussion 936-7.

9. Moinuddeen K, Quin J, Shaw R, et al. Anticoagulation is unnecessary after biological aortic valve replacement. Circulation. 1998;98 (19 Suppl):II95-8; discussion II98-9.

10. Babin-Ebell J, Schmidt W, Eigel P, Elert O. Aortic bioprosthesis without early anticoagulation-risk of thromboembolism. Thorac Cardiovasc Surg. 1995;43:212-4.

11. Turpie AG, Gunstensen J, Hirsh J, et al. Randomised comparison of two intensities of oral anticoagulant therapy after tissue heart valve replacement. Lancet. 1988;1:1242-5.

12. Gherli T, Colli A, Fragnito C, et al. Comparing warfarin with aspirin after biological aortic valve replacement: a prospective study. Circulation. 2004;110:496-500.

13. Hogue CW, Jr, Murphy SF, Schechtman KB, Davila-Roman VG. Risk factors for early or delayed stroke after cardiac surgery. Circulation. 1999;100:642-7.

14. Hogue CW, Jr, De Wet CJ, Schechtman KB, Davila-Roman VG. The importance of prior stroke for the adjusted risk of neurologic injury after cardiac surgery for women and men. Anesthesiology. 2003;98: 823-9.

15. Banbury MK, Kouchoukos NT, Allen KB, et al. Emboli capture using the Embol-X intraaortic filter in cardiac surgery: a multicentered randomized trial of 1,289 patients. Ann Thorac Surg. 2003;76:508-15; discussion 515 .

16. Cook DJ, Zehr KJ, Orszulak TA, Slater JM. Profound reduction in brain embolization using an endoaortic baffle during bypass in swine. Ann Thorac Surg. 2002;73:198-202.

17. Cook DJ, Orszulak TA, Zehr KJ, et al. Effectiveness of the Cobra aortic catheter for dual-temperature management during adult cardiac surgery. J Thorac Cardiovasc Surg. 2003;125:378-84.

\section{Discussion}

Dr John Chen (Honolulu, Hawaii). In this presentation, Dr Sundt and colleagues challenge the ACC and AHA guidelines for the use of warfarin therapy after implantation of biologic aortic valves. The ACC/AHA guideline for valvular heart disease is a 35-page comprehensive summary published in the Journal of Heart Valve Disease in 1998. The current guidelines recommend anticoagulation for the first 3 months with a target international normalized ratio (INR) of 2 to 3 . The evidence for support of the guidelines has been cited as class IC, which signified general agreement that anticoagulation is useful based on nonrandomized retrospective studies. The pathologic events leading to thromboembolism are activated platelets and factor XII. Platelet deposition and factor XII have been found on Dacron rings, and this is the impetus for their recommendation. The current AHA guidelines recommend that, after 3 months, warfarin can be discontinued in more than two thirds of the patients. The guidelines recommend lifelong anticoagulation in those with risk factors for thromboembolism, such as atrial fibrillation, previous thromboembolism, and hypercoagulable conditions. It is important to note that the published guidelines differentiate between valves in the mitral versus the aortic position, but the presented study is confined to only biological valve replacement in the aortic position.

I applaud the study group for directing our attention to the guidelines and questioning its validity. I must admit that our cardiac unit does not believe all patients receiving bioprosthetic aortic valves should be anticoagulated. Unfortunately, given the presented findings of an event incidence of $2 \%$ to $7 \%$ with a $1.2 \%$ difference in stroke and $2 \%$ difference in bleeding, this study like all those previously published is insufficiently powered to answer the question is early anticoagulation necessary after bioprosthetic AVR. A clinical trial of more than 40,000 patients would be required to answer this question. I have the following questions.

Is your nonanticoagulated group sicker than the anticoagulated group due to the fact that the anticoagulated group had a lower pump run and a higher operative mortality?

My second question refers to the percentage of anticoagulated patients receiving heparin prior to oral anticoagulation.

Finally, did your target INR vary depending on the valve brand used?

Dr Sundt. Thanks very much for those questions.

The first one, are the 2 groups really different, is obviously a difficult one and that is the Achilles heel in any retrospective study. You do the best you can looking back in the charts to see if they are comparable or not. As I said in the presentation, I think that the reason for the difference in the operative mortality is to some degree the patients that were particularly ill and died early on never made it to being anticoagulated. That is, however, only conjecture. I think the difference in the pump run is frankly a difference in which surgeons practice which approach. One of the surgeons who is particularly expeditious in his procedures is one of the ones who does not anticoagulate patients routinely. Ultimately I agree it is an almost unanswerable question, are the 2 groups different? Despite this, I was still struck by how similar the distribution of events was in the 2 groups.

I respect the criticism that the study cannot be adequately powered to reverse the current guidelines. I would argue, however, that it is at least as strong as the studies that support the guidelines. 
We are really left once again with the logical but unproven argument that we should administer anticoagulants until the sewing ring is endothelialized. I think that I would agree that this paper cannot answer the question any more rigorously than the other papers that claim one should anticoagulate.

As for the percentage of patients receiving heparin, I do not know that. We could go back and look at the charts for that. I can tell you, however, that this is the routine for the surgeons who do anticoagulate. This was quite striking to me. I had not seen that done before. I think the majority of those patients were treated with heparin early on and we could go back and look at that.

Did the target INR vary by prosthetic device? No, it didn't. The target INR was similar regardless of the manufacturer of the bioprosthetic valve.

Dr Chen. Were the valves studied pretty consistent across your entire group, that is, was it one particular valve used or multiple valves used?

Dr Sundt. Multiple valves were used over the course of that time period, so I suppose that is another potential confounding variable if there is a difference in thromboembolic risk among the valves. Perhaps there are differences in how much Dacron is on the prostheses, so I suppose that is a possibility. I would not have expected that, but I suppose that's a possibility.

Dr Vaughn Starnes (Los Angeles, Calif). It is a very timely topic, and I am glad you brought it to this meeting. We are finding our valve patients are very much older than they were 5 or 10 years ago. I think a lot of us have adopted this policy just because of the aged population we are operating on. Do you have any recommendations in terms: Is there age criteria that you are more prone to do this protocol versus a younger age patient, for example?

Dr Sundt. I actually do not anticoagulate early, and I think that this supports that practice. I think as the population ages it is more supportive of the notion of not anticoagulating people. That's really what my practice has been.
Dr Royce Calhoun (Sacramento, Calif). One thing to me that was just as impressive, as you pointed out, that the complication rate (ie, bleeding) is no higher, which I think is encouraging, so I guess one question for you and anyone that may know this, given that is sort of the official guideline that are often cited and where I trained we didn't use routine warfarin as well.

Dr Sundt. You did not.

Dr Calhoun. Did not, no. What is this situation if we do that and do not use warfarin and then somebody has a stroke and is litigious? Is that something that we have to worry about defending against? Do you know that?

Dr Sundt. Presumably, and that was part of the driver for doing this. It would be difficult to defend, I suppose, and these guidelines have enormous impact, enormous medicolegal implications. That is a factor as The Society of Thoracic Surgeons comes out with their practice guidelines as well. I think that the guidelines can really drive your practice and it is important to have good data for those.

Dr Calhoun. What is your protocol for mitral valves?

Dr Sundt. For mitral valves, I do exactly what the guidelines suggest actually, which is I anticoagulate them with warfarin. I have not used early heparin. In fact, at Mayo there is a tendency to use early heparin with mechanical or bioprosthetic valves, and I was accustomed to waiting until we were 5 days out, and, if we were not therapeutic, then starting heparin, but a more aggressive approach is used by some. I was surprised to see no more bleeding episodes than this.

Dr Chen. I'd like to address the issue of the guidelines. Because of this paper, I did sit down and read the entire 35 pages of this thing, and I must say that this is worth reading. The guidelines do specifically state that these are guidelines. These are not rules that are meant to be followed. They do allow room for individual patient treatment, and so I would refer to that, to say that these are the recommendations, but it is not an absolute rule. 